\title{
WHAT DID YOU SAY? - WHEN DESIGN STUDENTS MEET THE PROFESSIONAL LINGO
}

\author{
Kaare ERIKSEN, Ida Schütt MADSEN, Nanna Harboe FRIIS NORTOFT, Stefan LARSEN, \\ Rune GYNTZEL \\ Aalborg University, Denmark
}

\begin{abstract}
The industrial design profession in general relates to many different cross-disciplinary environments where words, phrases, slang and abbreviations from different scientific fields and practical domains mix with terminologies for specifically as well as rather vaguely defined phenomena. This creates a natural communication gap for industrial design interns in companies where they can meet a lingo that differs from the study environment at the university. This paper describes the nature of this communication gap based upon observations and surveys conducted among a group of industrial design master level students at a Scandinavian university. The research shows that the types and amount of unknown words and phrases vary according to the size of the company and the product categories in focus, but in all the cases slang and abbreviations in particular cause the design intern to ask for an explanation or simply exclaim 'What did you say?'
\end{abstract}

Keywords: Industrial design students, internship, lingo, language gap, professional lingo, communication, abbreviations

\section{INTRODUCTION}

This paper describes and analyses problems in linguistic communication and cognition for industrial design students who intern with companies. Collaboration in R\&D teams requires communicative skills in lot of different media, and industrial designers therefore often focus on visual techniques, constructive drawing and modelling in analogue or digital formats. Handling such skills and media is part of the basic communicative competencies and typically taught in university programmes in industrial design where the teachers to a certain extent evaluate whether the students master these communicative tools and skills sufficiently.

Designers, however, also learn their profession's written and spoken language while picking up and using terminologies of related professions and areas; especially if they are working in collaborative environments. Design teachers might wonder to what extent their students also have the sufficient linguistic skills to take part in fluent conversation and development processes in professional environments.

Donald Schön in his research investigated the communicative and reflective nature of problem solving in diverse praxis related professions [1]. He states that 'Engineering design is understandable as a reflective conversation with the materials of a situation' and made a famous analysis on the nature of communication between an architectural student, Petra, and her supervisor, Quist, where the creative process is enhanced by the use of associative terms with ambiguous meanings. However, it seems that there is no prominent research dealing with communication across specialisations or the communication gap from university studies to practice. Previous studies relate to communication across cultures, hierarchies and genders, communication using humour, gestures and communication of specialised knowledge to laymen by doctors and lawyers [2]. Professional use of abbreviations has also been handled and recognised as a problem in linguistic research [3].

The broad and collaborative nature of the field of professional industrial design means that candidates with the same educational background can end up in very different companies (from 1 to $100.000+$ employees), work with very different product areas (from furniture to cars or medical technical devices) and collaborate with a broad range of professionals (from doctors and acoustic engineers to carpenters and sales managers). Occasionally, this will lead to communicative gaps as the design educationists 
cannot introduce the students to the full diversity of words and terms used in so many different product areas, professions and company cultures that the designer could meet in practice.

Industrial design students (IDS) discover this gap when they are on their first internship in R\&D departments in companies, and their experiences of course mirror the situation for any new employee, but they also reveal to some extent whether certain areas were covered strong enough during their university studies.

To get a rough picture of the phenomenon, the authors of this paper asked five IDS to write down every specific new word they met during a four-month internship with Danish companies.

\section{COLLECTING AND SORTING THE DATA}

The amount of new words ( 312 in all) registered by the five IDS during their four-month internships can be seen in table 1, where you can also see the size of the company and the focus of each company where the five students spent their internships. The number of employees in each company ranges from $1+$ to $18000+$ and the focus of each of the different R\&D-departments ranges from loudspeakers (A-Speak), industrial pumps (B-Pump), pharmaceutical equipment (C-Pharm) and furniture (D-Furn) to household articles (E-House). In each case (A-E) the students listed every unfamiliar word including technical terms, metaphors, abbreviations or simply company jargon or slang.

In the following, the difference between words, terms and abbreviations is defined. A Word covers both terms and abbreviations. Abbreviations cover all words involving an abbreviation for example 'BICtime' or 'DIP-switch'. Terms are words not involving an abbreviation like 'Bass Tube' or 'Sub System Bus'. When the terms design education or design students (IDS) are used, they refer to a crossdisciplinary university study environment where aspects of manufacturing, usability, aesthetics, materials and business are integrated into innovative product proposals.

Table 1. The company types and number of words registered

\begin{tabular}{|l|l|l|l|l|}
\hline Student & Company focus & Company Size & New words registered & Nickname \\
\hline A. & Speakers & $200+$ employees & $\mathbf{1 3 3}$ & A-Speak \\
\hline B. & Pumps & $18000+$ & $\mathbf{4 3}$ & B-Pump \\
\hline C. & Pharmaceutical equip. & $4000+$ & $\mathbf{1 1 9}$ & C-Pharm \\
\hline D. & Furniture Studio & $5+$ & $\mathbf{1 1}$ & D-Furn \\
\hline E. & ID-studio & $1+$ & $\mathbf{6}$ & E-House \\
\hline
\end{tabular}

There is no scientific evidence in this research that shows that there are more new words to learn in a company that manufactures loud speakers, pumps or pharma compared to a (furniture) design studio as showed it table 1 . On the other hand, it probably comes as no surprise that the interns in big companies with hi-tech products, B2B-products or advanced chemical products met the most unfamiliar lingo.

Table 2 shows random examples of the words from all companies (A-E) collected by the students. The words, that have a (x2) next to them, in the list appeared in the reports from two different students on internship.

Table 2. Examples picked from the 312 specifically registered words in random order

\begin{tabular}{|l|l|l|l|l|}
\hline Spider & OCT & DPA & Stand Alone Product & DIP-Switch \\
\hline Basket & PoC & NPI & Hallway Prostitute & Design Freeze (x2) \\
\hline Ninja & USP's & RAL & Hooker's Measurement & Bass Tube \\
\hline Hooker & AOB & OEM(x2) & Sub System Bus & Needle Trap \\
\hline Pinol & EOD & CMF & Liver Pastry & CIM Module \\
\hline Design DNA & Retrofit & BIC-time & Stupid Models & Back-to-back \\
\hline
\end{tabular}

In general, the words were chosen using the following principle:

A. The words were only registered if their meaning was not understood

B. Words encountered in both conversation and company documents were registered.

C. When encountering words in a conversation, the students must be part of the conversation, as these situations confront the students with the lack in their professional language compared to overhearing a conversation between others. 
The words were analysed and subsequently categorised in the following five groups according to their meaning and context (table 3):

Table 3. Word Categories

\begin{tabular}{|cl|l|}
\hline Category & Meaning \\
\hline 1. & Area Specific word & $\begin{array}{l}\text { is tied to a specific knowledge area. For example, spider' } \\
\text { (speaker) and 'OTC': over the counter medication (medical) }\end{array}$ \\
\hline 2. & Organisational word & $\begin{array}{l}\text { is used to describe how the company operates. For example, } \\
\text { 'DPA': Device \& Packaging and 'Product Board' }\end{array}$ \\
\hline 3. & $\begin{array}{l}\text { Research } \\
\text { \& Development }\end{array}$ & $\begin{array}{l}\text { consists of words tied to areas within the design and development } \\
\text { process as 'Standalone product' and 'PoC': Proof of Concept }\end{array}$ \\
\hline 4. $\begin{array}{l}\text { Manufacturing } \\
\text { and Materials }\end{array}$ & $\begin{array}{l}\text { consists of words used in manufacturing sites, for example 'NPI': } \\
\text { New Product Introduction and 'ludermål' (whore measurement) }\end{array}$ \\
\hline 5. Miscellaneous & is for words that are not possible to categorise otherwise \\
\hline
\end{tabular}

These categories were defined by the students and they partly overlap, but they seem to give a relevant framework for analysing the lingo. The words could also be categorised in other ways or with another focus. For instance, some of the students chose to analyse to which extent the unfamiliar words could be categorised as slang or jargon.

\section{DIFFICULT 'AREA SPECIFIC' TERMS}

On average, the most unknown words to the students were found in the area specific and organisational categories while there were fewer in the miscellaneous, manufacturing and materials and the fewest words in the design and development category. This distribution does not seem surprising, as words in relation to design and development should be part of the students' basic language as used on a daily basis in lectures and discussions in project groups at the university, that is based on Project Based Learning principles (PBL).

The unknown area specific words would naturally be more prominent as most of the students were interns with companies that manufacture very specialised or high-tech products that the students had no prior knowledge of. This tendency was dominating especially in the companies that manufacture loudspeakers (A-Speak) and pharmaceutical devices (C-Pharm).

The simple fact that most of the students had little or no professional experience from employment with companies meant that many of the management terms (such as the '3P-principle': Predict, prevent and protect or 'Q-dept': Quality Department) were new to them and therefore boosted the organisational category.

Most of the students registered approximately $1 / 3$ of the words in the area specific category (such as DIP-Switch and Bass Tube and Sub System Bus), which made it the biggest category in general.

The number of manufacturing and materials words registered in the medium sized loudspeaker company (A-Speak) was surprisingly high, while there were fewer words in the organisational category. This proved different in the pump company (B-Pump) with 18000+ employees. In the big B-Pump company the organisational words registered (such as GRM, GPC and UFH: all being internal company abbreviations) made it the biggest category with surprisingly few words in the manufacturing and materials category.

The student who made the observations in the B-pump company also noticed that the strange abbreviations used for everything seemed to be a kind of an internal joke in the company. She also noted when asking for the meaning of some abbreviations that some employees didn't know what the abbreviation exactly stood for, but they know the overall meaning of it and how to use it. The company has tried to eliminate this phenomenon by making a company-dictionary of the abbreviations which are used in the company.

The basic task of collecting words, thus gave the students several layers of insight into the role of the professional language in contemporary research and development departments, although they have no general statistical validity per se. The simple listing and comparison of the frequency of use and the importance of using different word categories (table 3) showed that there IS a latent language barrier for students (and newly graduated candidates) when meeting the professional context. The challenges differ depending on the size of the company and the complexity and technical depth of the products or the 
prior familiarity with the company's products, but probably also due to other aspects such as the use context, markets etc.

The observations also showed that there is a social factor at play when using the company language. If a person does not understand the lingo in detail, they might very quickly be left behind in a conversation, as the ability to "play along" in a communication situation seems to be more important than knowing the exact meaning of the word or abbreviation that is being used.

\section{THE MYSTERIOUS LAND OF STRANGE ABBREVIATIONS}

A specific problem, therefore, relates to the use of abbreviations in practice. Abbreviations dominate the lists of new words observed at the internships. $41.3 \%$ of the words from A-Speak, $88.4 \%$ of the words from B-Pump and $52.1 \%$ from C-Pharm were abbreviations.

Zipf's law of abbreviation states that there is a relation between the length of a word and the frequency of its use. Words that are used often are shorter. Recent studies have shown this to be a universal law across languages [4]. It even reaches as far as to the animal kingdom, where studies of dolphins and monkeys conclude that the law is a natural law. It is simply natural to want to express yourself as efficiently as possible. Hence, you cannot avoid words being abbreviated, but in the process of abbreviation, the word loses part of the (or the full) connection to the original word or word constellation and the connection to previous experiences and knowledge that you need in order to understand or interpret it. The tendency to use abbreviations in companies might therefore lead to more efficient communication within an already existing team but causes inefficient communication with newcomers and might even unintentionally strengthen existing hierarchical structures or misunderstandings, as the newcomer might feel awkward asking for the definition of a term in the midst of a conversation.

Even though the area specific category had most words in general, it appears that the problem with understanding abbreviations was more prominent in the category organisational. This was apparent when the abbreviations were removed from the list of words, hence reducing considerably the numbers in the categories of organisational and miscellaneous words.

This indicates that the biggest problem with organisational terms is not the category itself, but the number of abbreviations in the category. For example, the term "End of the Day" would not have been registered as an unknown word if it had not been abbreviated to 'EOD'.

The students' systematic and thorough registration of unfamiliar terms also gave the university supervisor a fine overview of common words and abbreviations that you might have expected the students to know at this level.

A phenomenon such as 'CMF' (meaning Colour, Material, Finish) was on the list, as was 'OEM' (meaning Original Equipment Manufacturer), 'Design Freeze' (reported twice) and 'CEO'. The students' registration of unfamiliar words in internships may lead to considerations about upgrading the professionally related lingo used in university lectures and supervisions in order to make sure that the most common terms are understood. At least in areas that cover most company types relevant for IDS internships.

\section{NINJAS AND HALLWAY PROSTITUTES}

Two interns employed in smaller design studios (D-Furn \& E-House) focused on the phenomena slang and jargon among the new words they heard in daily conversations, as they found that these word categories seemed to have a special and often important role in the design process. There are several different interpretations of the definition of these two phenomena. The language researcher Walter Nash defines jargon as a terminology used in professions, occupations or pursuits [5]. He also states that 'Every activity has its occupational terms, many of which cross the bounds of technical usage and enter into common parlance'. As an example, this has happened in several instances from the jargon of the computer industry, e.g. when a computer is 'down', and when it is 'up and running'. Nash points towards jargon in the modern interpretation being related to groups that share a common activity or, in relation to preliminary research, work together. Hudson [6] states that there is a difference between jargon and technical language and that the technical language is essential to every profession, and without it the professions' members cannot express themselves, thus making it impossible to develop theories and do research within that field. According to George Yule, 'jargon is a special technical vocabulary associated with a specific area of work or interest. In social terms jargon helps to create and maintain connections among those who see themselves as insiders in some way and to exclude outsiders [7].

The line between jargon and slang is somewhat blurred and slang also has many different definitions. 
Connie Eble [8] states that slang is a set of words or phrases that speakers use to establish or reinforce social identity or cohesiveness with a group. She also states that the complexity of slang makes it difficult to define. She uses these four criteria for slang, originally proposed by Dumas \& Lighter [9].

1. Its presence will markedly lower, at least for the moment, the dignity of formal or serious speech or writing.

2. Its use implies the user's special familiarity either with the referent or with the less statusful or less responsible class of people who have such special familiarity and use the term.

3. It is a tabooed term in ordinary discourse with persons of higher status or greater responsibility.

4. It is used in place of the well-known conventional synonym, especially in order (a) to protect the user from the discomfort caused by the conventional item or (b) to protect the user from the discomfort or annoyance of further elaboration.

Dumas and Lighter conclude that when an expression fits at least two of the above-mentioned criteria, the term can be considered slang.

The difference between jargon and slang therefore seems to be that jargon relates to groups engaging in a common activity or profession, whereas slang refers to social groups and is often seen as informal language in contrast to jargon.

According to Julie Coleman [9], some jargon originates from slang, thus cementing the similarities between the two, and proposes 11 conditions that optimally need to be present in order for slang to develop within a group:

1. A standardised, official, or accepted form of the language which it exists within and rebels against

2. A hierarchy

3. A real (or perceived) threat to individuality and self-expression

4. A sense of group identity at the bottom of the hierarchy

5. An awareness or belief that conditions could be better

6. Frictions within the group that can only be expressed verbally

7. Linguistic variation within the group

8. Dense social networks

9. Continuity, but not too much

10. Fear (or some form of pressure)

11. Some toleration by those in authority.

In addition to the 11 conditions, Coleman (2012) also finds that in order for slang to develop, there needs to be some sort of creativity present, as it takes creativity to make up new words, or use words to describe other aspects.

The two student interns in smaller studios (D-Furn \& E-House) both felt that they found themselves in a dense, creative and dynamic atmosphere where they were challenged and involved also on a personal level. They sat close in the studio settings, where practically all work took place in the same room where everyone could follow and comment on each other's behaviour, attitude and work.

While there would be an obvious hierarchy in each of the studios ranging from the owner/s (high status) to the interns (lowest status), they observed a certain category of slang or jargon that was not developed as a result of hierarchy, threat to individuality, bottom group identity or fear as mentioned in Coleman's list.

One of the interns experienced a discussion among the furniture designers, where they argued whether the product proposal should be more or less Ninja. Although this word is not a formal term taught at design schools when discussing form and aesthetics, the designers all seemed to understand the word and its meaning in this specific context when discussing the design of a modern Scandinavian chair with no connections to feudal Japanese samurais. This slang word was not a rebel against a standardised official language (see point 1 in Coleman's list) but simply a word that described an intended expression or a feeling referring to a phenomenon probably only known from the popular culture. In that perspective the word Ninja can be seen more as jargon probably invented 'on the spot' as an effective term to ease the reflection in action as described in the creative processes by Schön [1].

The interns reported words that according to Dumas \& Lighter are closer to the slang category. The words 'Ludermål' (translated to whore's measure, meaning that you tell the size by rough estimation) and the word 'Hallway Prostitute' (the English word is used without translation, meaning Facers at furniture fairs) were registered by the students, who did not understand the meaning of the words and had them explained. The words both use tabooed terms, hence diminishing or satirising over a phenomenon. They both 'lower, at least for the moment, the dignity of formal or serious speech' [9], 
but they make sense when explained and probably also to a certain degree create a sense of group identity or bonding although not necessarily related to a position at the bottom of the hierarchy as mentioned in point 4 in Coleman's list.

\section{WHAT TO LEARN}

The validity of the research results obtained might be questioned due to the small number of participants and the results are certainly also depending of the students' background and the related study environment. Whether the word categories in table 3 are clear or relevant might also arguable, but the authors of this paper hope that these uncertainties can be clarified in future studies. The research project challenged the professional and academic background of the researcher and students involved in several ways, as linguistics is not a natural part of the syllabus for design educations and the linguistic research community has few connections if any with contemporary design research. Nevertheless, the task of registering unfamiliar terms gave new insights and prompted discussions in the group of industrial design teachers and students at the associated university. To what extent can students be prepared to meet the language gap and to what extent should the students know more basic organisational terms? To what extent should the language used when discussing form and aesthetics at the university involve more metaphoric language (Ninja-words) as a supplement to more basic terminology from form-theory (convex/contrast/balance-words)?

Another spinoff was subtler as the given university-task strengthened the students' awareness of and focus on situations where they might be in danger of being cut off in a discussion and gave them the strength to break the awkward situation and simply ask: What did you say?

\section{REFERENCES}

[1] Schön D. The Reflective Practitioner, 1983 (Basic Books, inc, Publishers, New York).

[2] Gunnarson B. Professional Discourse, 2009 (Continuum International Publishing Group, London).

[3] Steinhauer A. Sprachenökonomie durch Kurzwörter - Bildung und Verwendung in der Fachkommunikation, 2000 (Gunter Narr, Verlag Tübingen, Tübingen).

[4] Bentz C. and Ferrer-i-Cancho R. Zipf's Law of Abbreviation as a Language Universal, 2016 (Universität Tübingen, Tübingen).

[5] Nash W. Jargon: Its uses and abuses, 1993 (Blackwell Publishers, London).

[6] Hudson K. The Jargon of the professions, 1979 (Macmillan Press, London).

[8] Yule G. The Study of Language. $3^{\text {rd }}$ edn. Cambridge, UK, 2010 (Cambridge University Press, UK).

[9] Dumas B.K. and Lighter J. Is Slang a Word for Linguists, American Speech vol 53, no.1, pp.517, 1978, (Duke University Press).

[10] Coleman J. The Life of Slang, 2012 (Oxford University Press, UK). 